\title{
Study of Volatility Stochastic Processes in the Context of Solvency Forecasting for Sri Lankan Life Insurers
}

\author{
Ashika Mendis \\ Business School, University of Bedfordshire, Bedfordshire, UK \\ Email: ashi.ronnie@gmail.com
}

How to cite this paper: Mendis, A. (2021) Study of Volatility Stochastic Processes in the Context of Solvency Forecasting for Sri Lankan Life Insurers. Open Journal of Statistics, 11, 77-98.

https://doi.org/10.4236/ojs.2021.111004

Received: December 4, 2020

Accepted: January 17, 2021

Published: January 20, 2021

Copyright $\odot 2021$ by author(s) and Scientific Research Publishing Inc. This work is licensed under the Creative Commons Attribution International License (CC BY 4.0).

http://creativecommons.org/licenses/by/4.0/

\section{(c) (i) Open Access}

\begin{abstract}
The main business of Life Insurers is Long Term contractual obligations with a typical lifetime of 20 - 40 years. Therefore, the Solvency metric is defined by the adequacy of capital to service the cash flow requirements arising from the said obligations. The main component inducing volatility in Capital is market sensitive Assets, such as Bonds and Equity. Bond and Equity prices in Sri Lanka are highly sensitive to macro-economic elements such as investor sentiment, political stability, policy environment, economic growth, fiscal stimulus, utility environment and in the case of Equity, societal sentiment on certain companies and industries. Therefore, if an entity is to accurately forecast the impact on solvency through asset valuation, the impact of macroeconomic variables on asset pricing must be modelled mathematically. This paper explores mathematical, actuarial and statistical concepts such as Brownian motion, Markov Processes, Derivation and Integration as well as Probability theorems such as the Probability Density Function in determining the optimum mathematical model which depicts the accurate relationship between macro-economic variables and asset pricing.
\end{abstract}

\section{Keywords}

Risk Management, Insurance Sector Sri Lanka, Risk-Based Capital, Brownian Motion, Risk Charges, Capital Forecasting, Stochastic Processes, Volatility Models

\section{Introduction}

The key determinants of a successful Service-Based Organization in Sri Lanka are Customer Relationship, Pro-activeness, Commitment and Effective Controls 
[1]. In the past decade, the economy has indicated a shift towards the Service Sector and therefore contains vast potential. Studies have proven that Perceived Brand Equity has a high correlation with Purchase Intention and therefore strategies could be aimed at optimizing Perceived Quality, Brand Loyalty, Brand Awareness and Brand Association [2]. Therefore, all decision making of an Insurance Company in Sri Lanka must be data-driven and this data must be processed and analyzed correctly through appropriate mechanisms.

An Insurance company faces the threat of negative impacts on its Business Continuity and Potential through incompetent and ineffective internal mechanisms as well as external forces. Such Risks can be prioritized, and its impact calculated based on the probability of occurrence. The importance of this method is that it considers the holistic picture of a certain scenario and thereby allows the company to minimize or avoid the associated impact [3]. As an Insurance Company's regulations are centered on Risk-Based Capital Charges, appropriate risk detection and contingency planning are of paramount importance in terms of Strategic Planning [4], especially given that external forces have a significant impact on Risk-Based Capital [5].

Actuarial Science helps determine the appropriate pricing for products through Mortality and Morbidity studies of contemporary customer segments as well as Risk Pricing for all perceived Risks. However, Underwriting Risk and Reinsurance Risk significantly impact the profitability of the Insurer caused by underpricing of premiums and insufficient reinsurance coverage for claims, respectively. The root cause of these risks is incorrect assumptions on which all Insurance Pricings are based [6]. The accuracy of these assumptions can be enhanced through high quality data analytics via statistical tools [7].

\subsection{The Problem}

Research indicates that studies into appropriate Statistical Risk Modelling in the Sri Lankan Insurance Industry are almost non-existence. While many theoretical approaches have been explored through research, it is highly lacking on the technical and mathematical end. Additionally, the country's Risk Management methodologies within the industry still are not integrated with data and statistical analysis and are far from integrated modelling. As such, this paper aims to contribute to filling this gap by deriving a Stochastic Volatility Model which monitors and forecasts the movement of Risk-Based Capital. This paper serves as the foundation of a series of researches which aim to create an automated system for real time capital projection.

\subsection{Perceived Outcome}

The overall outcome of this exercise is to derive a statistical capital projection model that is suitable and relevant to Sri Lankan Long-term insurers. The outcome of the model provides the company information on the factors which impact capital, external forces which cause volatility and its interrelationships. It 
also provides the future direction of capital and its influencing factors. Therefore, the company's strategic decision-making process can be aligned to the predicted capital movements and thereby cascaded down to operational and business horizons. This provides a statistic driven risk management system enabling the company to achieve its strategic objectives amid volatile environments.

\subsection{Contemporary Evidence}

Stochastic Process Algebras are used in Dependability Modelling where the components of the holistic system influence each other. Stochastic Volatility Modelling includes components which fluctuate over time. The model is kept together by a set of equations which are based on the historic relationships of the components and can forecast the movements of the entire system [8]. This is especially useful in Statistical Risk Management in terms of monitoring and forecasting the movement of Risk-Based Capital.

\subsection{Literary Abstract}

The Sri Lankan Financial Industry has had a turbulent past tainted with fraud, anti-money laundering and political manipulation which resulted in the European Commission listing the country as high financial risk. Furthermore, the era of peace bought with a 32-year-old only lasted $5-6$ years as political instability returned through scandals and unconstitutional political upheaval.

The Insurance Sector went through ups and downs in the past decade. The decline in motor vehicle registration declined the General Insurance business while process integration and automation enhanced the quality of service and margins. Product innovation has created diversification both in terms of products and distribution channels. However, majority of the market remains unpenetrated as the deep inbuilt distrust regarding the Financial Industry hampers potential. However, Enterprise Risk Management and a series of Merges and Acquisitions boosted the capabilities of the Industry through the years.

The conundrum of ageing population seems to be doing the industry a favour as it has increased the burden of dependents on a contracted labor force. Therefore retirement products, health riders and life covers have taken forefront of consumer behavior. This was only enhanced further by the COVID-19 pandemic.

The gig economy has helped improve the management of Agents. However there is a near possibility that much of the services exposed to customers will be automated and digitized through insuretech.

An ERM system is a management skeleton which must be adopted and customized as per the company's objectives and circumstances. A set of risk-centric corporate objectives are enforced, monitored and controlled through risk identification, assessment and response. A neural communication network is bound around risk-silos (sub risk segments) and reporting is executed through these networks.

A solid ERM must be able to forecast the cost of capital of doing business for 
the entire lifetime of liabilities, which usually average at 25 - 30 years in the Life Insurance business. A Russian study revealed the devastating fact that many Insurers experience diminishing returns due to incorrect valuation of future margins. As such, forecasting plays a main role in Risk Management systems. However, as forecasting risks are complicated by a vast pool of fluctuating variables which in turn are influenced by external forces, a sound mathematical approach must be adopted to the ERM in terms of forecasting required capital. This is the cornerstone of strategy and capital allocation.

Required Capital is the solvency necessary to bear business risks. Many tools are available for Capital Budgeting such as game theory, real options pricing, decision trees sensitivity analysis, scenario analysis, and IRR, NPV and uncertainty absorption cash flow. However, many of these lack a quantified function of variable market forces.

One developed method is to calculate Risk-Adjusted Performance Measure which is expected revenue net of expected losses and costs divided by economic capital. Another method is to calculate Economic Capital as the excess of riskadjusted assets and risk-adjusted liabilities by discounting assets and liabilities using Value at Risk.

However, Value at Risk is based on current market conditions and lacks a volatility component spreading out into the future. This was somewhat resolved by EWMA although it disregards asymmetry.

Engel's ARCH model incorporated conditional variances fluctuating over time but is expressed as a function of historical trends, and therefore can only be applied to a single period of forecast. This time component is corrected in Bollerslev's GARCH model.

However, Stochastic Volatility (SV) proved to be the most accurate in terms of forecasting based on fluctuating variables which are in turn dependent on other variables. The soundest SV model is the Brownian motion where all variables are considered to be influenced by surrounding variables. Therefore, the relationship between each independent variable can be linked in one quadratic equation using integrated variables. When deriving the relationship between these independent variables, Pearson Coefficient can be used to quantify the said relationship thereby incorporating linear coefficients within integrated variables. However, this is the first step in establishing the model and is thereby far from the optimum quantification standard of industry influencers.

\subsection{Literature versus Observation}

The RBC Rules calculate CAR in a similar manner to that of Boonen's SCR model with slight differences. The SCR only takes into account Interest, Equity and Longevity Risk while RBC includes a wider spectrum. However, this makes forecasting more difficult under the RBC model than the SCR model. The principle behind RBC is similar to the base of VaR, the only difference is VaR being undefined while RBC provides a risk model. 
The EWMA method is not practical as it assumes that the market follows a normal distribution. The ARCH and GARCH models were superseded by the Stochastic Volatility Model.

$\mathrm{RBC}$ includes stochastic processes in various parts of its model. For instance, when assets and liability mismatches are factored into capital, Macaulay's duration is used to stress the portfolios while incorporating the RFR as the independent variable. The Macaulay's duration calculation is thereby a Brownian motion embedded within RBC.

When forecasting the movement of independent variable, Pearson's coefficient can be calculated to forecast various economic indicators which are then used in RBC stochastic modelling.

As the given parameters under the RBC Rules are regulatory, the company's internal Risk Management system should have a customized version of RBC while maintaining buffers as per the Risk Appetite. Here, Alawattagama's ERM process can be adopted. However, the Financial Flows derived by the Russian study does not incorporate a risk-centric system and focuses only on financial management. Therefore, $\mathrm{RBC}$ risk categorization and definitions can be structured into this ERM process while the limits and risk charges are stressed to give a model customized to the company's risk appetite.

\section{Methodology}

The Research Onion methodology was adopted when producing this paper. It is an outside in method which follows a systematic approach in deciding the correct methodology for each research component [9].

\subsection{Research Philosophy}

The collective set of norms, beliefs and idiosyncrasies associated with the objective reality of the research topic forms the Research Philosophy. Saunders details three different Philosophies, namely Ontology, Epistemology and Axiology.

The philosophy surrounding this study is a mix of Constructivism and Realism. Different theories are explored in the perspective of different scholars in order to adopt or derive theories that are suited to Life Insurers of Sri Lanka, while existing relationships between variables are explored through Realism.

\subsection{Research Approach}

With the chosen philosophical mindset, the research can be approached in one of three ways: Deduction, Abduction and Induction.

This research has been approached inductively. Literature inference was utilized prior to drafting the proposal in determining Stochastic Volatility Processes to be most suitable for Capital Projection. However, this is not looked at in isolation and therefore specific hypotheses were not formed. Rather, all related theories were studied in order to create a suitable model equipped with stochastic volatility processes and related theorems. 


\subsection{Methodological Choice}

Given that this research involves a quantitative metric (Capital) which is influenced by qualitative forces (External environment), a multi-method research was conducted through mathematical, economic and business Literature where quantitative and qualitative findings and principles were incorporated.

\subsection{Strategy}

Strategy defines how research expectations are realized. Strategies include experiment, survey, archival research, case study, ethnography, action research, grounded theory and narrative inquiry.

The strategy used to realise research objectives of this paper is multiple case study through systematic review.

\subsection{Time Horizon}

This research studies past trends extensively in order to generate relationships between variables. As such, a Longitudinal Time Horizon was selected.

\subsection{Techniques and Procedure}

Existing literature on conceptual frameworks was collected in order to study different perspectives in terms of Capital Valuation, Risk Management methodologies and Stochastic Volatility processes. The source for this was mainly academic journal papers. In order to study past trends, publications of statistical data on historic performance in terms of economy and the insurance industry were collected. These are mainly reports and publications by Government or Regulatory bodies, mainly through the databases of CBSL, CSE and IRCSL. Newspaper articles and journal papers pertaining to the events of the insurance industry were collected in order to ascertain the nature and evolution of same.

The literature pertaining to the Insurance Industry of Sri Lanka, Capital Valuation, Risk Management methodologies and Stochastic Volatility processes were first studied in order to understand the underlying concepts and calculation bases. Historic data was then analyzed to form trends and correlations in order to form relationships between variables. The prevalent Stochastic modelling (RBC) within the country was then studied to understand if all necessary aspects are being addressed. Where necessary, the knowledge from existing studies relating to mathematics was used to improve or fill the gaps in the RBC model.

\subsection{Systematic Review}

Systematic Review collates and evaluates data in order to answer the specified research question while meta-analysis helps infer quantitative data with qualitative literature. The PRISMA model was adopted for this purpose [10], which details a journey through the collected data through the stages of identification, screening, eligibility testing and inclusion.

Systematic review follows seven stages, namely setting research scope, infor- 
mation flow, and evaluation of information quality, listing sources included in review, descriptive summary, thematic analysis, and conclusion.

Denscombe details four methods of thematic analysis, namely meta-analysis, narrative analysis, thematic synthesis and realist synthesis [11]. When compiling this paper, thematic synthesis was used to review selected articles in order to derive research themes and questions. Meta-analysis was used to critically evaluate historic literature and data in order to derive conclusions on the selected themes. The research was then conducted in line with set objectives, both in terms of literature review and data analysis. To study the stochastic volatility processes in order to derive the algorithms defining the relationship between volatile market forces and the company's Capital.

\section{Literature Review}

\subsection{Regulatory Risk-Based Capital}

Risk-Based Capital (RBC) is the capital required to assure solvency while managing uncertainty [12]. This must be based on a market consistent valuation methodology as it shows the management the liquid assets available to absorb market shocks. Additionally, RBC has been used as the base for prudential and solvency regulations under the BASEL series (BASEL III is currently under enforcement). RBC is also known as Economic Capital.

Corporate Management has long since moved from cash flow management to risk-based management. In relation to the insurance industry, Risk Based Capital uses Return on Risk-Adjusted Capital and Return on Equity as proxy in determining whether the business is being adequately compensated for the risk underwritten through policy issuance. This centers the focus of Corporate Strategy on Capital Management, thereby deeming Capital Projection and Capital Allocation as cornerstones of Strategic decision making.

Solvency can be achieved by maintaining the minimum capital requirement. The most crucial factor in capital management is determining the level of capital required in order to cover its portfolio risks in the relevant timeframe. Therefore the timely identification and quantification of such risks are mandatory in maintaining solvency alongside key performance targets. Some tools used in Capital Budgeting include game theory, real options pricing, decision trees, sensitivity analysis, scenario analysis, IRR, NPV and uncertainty absorption cash flow [13].

\subsection{Risk-Based Capital as a Stochastic Process}

Available Capital stipulates the Economic Value of a company's Capital (Economic Capital) and must exceed the Minimum Capital Requirement (Risk-Adjusted Capital) in order to be solvent. Available Capital is the collective Economic Value of Assets (A) and Liabilities (L) and can be expressed as stochastic processes incorporating the variable time, stipulating that Assets and Liabilities must independently be greater than 0 at any given time. Therefore, Economic Capital is the excess of Assets of Liabilities. As per Solvency Regulations, it is calculated 
with the assumption that there are zero future underwritings. Risk-Adjusted Capital subtracts the Value-at-Risk of the assets and liabilities and thereby calculates Capital as the excess of risk-adjusted assets and risk adjusted liabilities, incorporating risk of future business [14].

\subsection{Risk-Adjusted Performance Measurement (RAPM)}

RAPM provides a single performance measurement based on Solvency rules and is therefore a much more realistic forecast of shareholder's returns.

$$
\text { RAPM }=\frac{\text { Expected Revenue }- \text { Cost }- \text { Expected Losses }}{\text { Economic Capital }}
$$

where expected revenue and losses are mutually exclusive [15].

However, even though the regulatory definition dictates the above, there are practical issues when it comes to calculating Economic Capital and Risk-Adjusted Capital based on the aforementioned theory. Given that Economic Capital is basically a conversion of Balance Sheet Capital into economic value, it is inevitable that a time component is factored in as assets and liabilities are economically valued as the present value of future cash flows. Therefore, if the capital required by the company and the available capital of the company are both subjected to the time component, then at the point the two equates, the solvency ratio becomes a factor of one, thereby providing a corrective and accurate measure of the company's liquidity and financial position.

In terms of Solvency 2 Regulations, it is assumed that Capital of a Bank and Insurer provides $99 \%$ and $99.5 \%$ guarantee respectively, that obligations will be met by the company. Therefore required capital here is calculated by subtracting the capital Value-at-Risk (VaR) at $99.5 \%$ confidence level. However, this could be the making or breaking point of Capital Management as this calculation requires a series of dependent and independent assumptions. If the company is over-optimistic it gives rise to the risk of insolvency in the future while over-cautiousness could create opportunity cost, foregoing probable positive cash flows.

Dacorogna suggests a series of equations with probable conditions and rationale [14]. However, given that the risk components for each company differ depending on strategy, segmentation, size and demographics, it is prudent to calculate both economic capital and required capital on the basis of recognized risks as per the company's capital structure. Hence, the company must have a clearly defined capital structure cascading down to risk components. In hindsight, this is where the Risk-Based Capital structure becomes most relevant.

\subsection{Value-at-Risk (VaR)}

VaR is typically the loss impact through the worst case scenario under normal or expected market conditions and can be calculated in both parametric and nonparametric methods. Non-parametric methods deviate from predictive analysis and calculate VaR through historic trends. The Historic Simulation method uses the base assumption that the considered future is similar to the recent past while 
the non-parametric density estimation method takes a weighted average of expected losses across worse to best scenarios and treats the highest density area as the probable range. On the other hand, parametric methods utilize probability in calculating VaR [16].

\subsection{Exponential Weight Moving Average Model (EWMA)}

If the probability distribution is assumed to be normal then EWMA can be used [17] to estimate $\sigma_{\dot{t}}$

$\mathrm{VaR}$ at confidence level $1-\alpha=\mu+\sigma_{t} G-1(\alpha)$ where $G-1(\alpha)$ represents the $\alpha$ quantile of the standard normal distribution while $\sigma_{t}$ is the standard deviation of portfolio returns.

$$
\sigma_{t}(1-\lambda)^{1}=\sum_{j=0}^{n-1} \lambda^{j}\left(\epsilon_{t-j}\right)^{2}
$$

The main drawback of this method is the assumption that the dataset will follow a normal distribution which is improbable due to market volatility and uncertainty and are usually observed to follow a negatively skewed leftist distribution. Furthermore, while EWMA factors in varying and cluster volatility, it leaves out asymmetry and leverage.

\subsection{Volatility Models}

Volatility models seem to somewhat abate the aforementioned shortcomings. Three widespread volatility models are GARCH family, Stochastic Volatility Model and Realised Volatility Based Model.

\subsection{Autoregressive Conditional Heteroskedastic (ARCH) and Generalized Autoregressive Conditional Heteroskedasticity (GARCH)}

In the $\mathrm{ARCH}$ model introduced by Engle, conditional variance fluctuates over a given period of time as a function of historic errors thereby having a constant unconditional variable. This is mostly accurate for a single period forecast. The model provides a risk scoring mechanism based on likelihood of occurrence [18]. Bollerslev's GARCH model on the other hand generalized Engle's ARCH with corrections on the forecast period limitation and flexible lags [19].

\subsection{Brownian Motion and Samuelson-Black-Scholes Model}

Stochastic Volatility can be introduced to traditional Samuelson-Black-Scholes model in calculating the log price of an asset by introducing Brownian motion and Volatility parameters. Brownian motion is a double random effect where the direction of one variable is influenced by the motion of other surrounding factors [20]. The volatility component can be defined through random time to incorporate continuity and acts as a chronometer. Therefore:

$$
y^{*}(t)=\beta t+\sigma w(t)
$$


where $w$ is the Wiener Constant with drift $\beta$ (random walk) and random shock $\sigma$ which is then converted to:

$$
y^{*}(t)=\beta \tau^{*}(t)+w\left(\tau^{*}(t)\right) \text { With random time } \tau
$$

If time is to be attached with a positivity condition where $t>0$, the first formulae can be rewritten as:

$$
y^{*}(t)=\mu t+\beta \tau^{*}(t)+\int \sqrt{\tau(s) \mathrm{d} w(s)^{1}}
$$

where $\tau(t)$ has replaced the usual variance $\sigma^{2}$ with a drift where the integral:

$$
\tau^{*}(t)=\int_{0}^{t} \tau(s) \mathrm{d} s
$$

where $\tau^{*}$ functions as the integrated variance.

However, a customized formula must be derived if the actual proportions and relativity of the factors impacting forecasting metrics with the progression of time. This deserves a separate paper. In order to derive a sound Stochastic Volatility model, analytical option pricing, realized variance and realized power variance, OU based models and subordination must be integrated into multivariate models [21].

\subsection{Solvency Capital Requirement (SCR)}

An alternative approach calculated the SCR under Solvency II as a function of sub risk categories, namely equity risk and market risk [22].

$$
\mathrm{SCR}_{m k t}=\sqrt{M k t_{e q}^{2}+M k t_{i n t}+2 A * M k t_{e q} * M k t_{i n t}}
$$

where $e q$ is Equity Risk, int is Interest Risk and $A$ is the up and down shocks.

Balance of Funds is calculated by deducting Best Estimate Liabilities (BEL) from Assets. As with interest, the capital requirement for equity shock is simply the amount by which the company's capital reduces once a shock impact is factored into Equity. If longevity risk is further incorporated to the equation, then the portfolio risk when subjected to mortality metrics gives the expected risk arising through claim expenses. If both equity risk and interest risk can be expressed as a function of SCR at market prices, then the overall SCR can be calculated as follows:

$$
\mathrm{SCR}_{m k t}=\sqrt{\mathrm{SCR}_{m k t}^{2}+\mathrm{SCR}_{\text {long }}^{2}+0.5 * \mathrm{SCR}_{m k t} * \mathrm{SCR}_{\text {long }}}
$$

Here, the selected or derived equation must include a positive time component when projecting capital, purely on a mathematical basis. Brownian motion inculcates the natural market phenomena of external environmental influence which enables the equation to host more than one independent variable interconnected through an integral or integrated variance while Boonen's SCR incorporates risk imposed through sub risk categories on overall capital. A prudent integration of these two methodologies would be to incorporate Brownian motion to the independent variables while maintaining the relationship of the dependent variables as per Boonen. 


\subsection{Pearson's Coefficient}

Pearson Coefficient $(R)$ calculates the strength and nature of the linear relationships between two variables [23]. The coefficient can be calculated on excel using the formula $=$ PEARSON (array 1, array 2) where the arrays represent the data sets of the two variables [24]. The result is an integer ranging from -1 to +1 and can be interpreted as follows:

$-1<R<-0.5$ : Strong negative

$-0.5<R<0$ : Weak negative

$1<R<0.5$ : $\quad$ Strong negative

$0.5<R<0$ : Weak negative

It can also be plotted on a scatter diagram on excel for graphical representation. $R$ is mainly useful when forecasting a dependent metric.

In this paper, $R$ is used to determine and confirm the macro-economic variables which impact $\mathrm{RBC}$ in the context of Sri Lanka in order to determine the depended and independent variables which must be subjected to the theoretical conclusion of the Literature Review.

\section{Discussion}

\subsection{Calculation of Risk-Based Capital}

Solvency Margin (Risk-Based Capital) Rules 2015 under the Regulation of Insurance Industry Act, No. 43 of 2000 stipulates a much more comprehensive and inclusive Risk-Based Capital calculation format for Solvency. Capital Adequacy Ratio (CAR) is proxy for solvency and the minimum requirement is $120 \%$. Insurers are further required to maintain minimum Rs. 500 Million of Total Available Capital (TAC). TAC is the aggregate of Tier 1 and Tier 2 Capital net of Deductions and Tier 2 Capital cannot exceed 50\% of Tier 1 Capital. Tier 1 and Tier 2 Capital are the Equity and Debt components of Capital while Deductions are assets inadmissible as per RBC Asset Rules and Determination 14.

CAR is basically an expression of TAC as a percentage of Risk Capital Required $(\mathrm{RCR})$, i.e. $\mathrm{CAR}=(\mathrm{TAC} / \mathrm{RCR}) * 100 . \mathrm{TAC}$ represents the actual capital while RCR represents the total capital required to cover the entire risk portfolio. Total risk of the company is calculated through the following sub risk categories;

- Credit Risk Capital Charge (CRCC)

- Concentration Risk Capital Charge (COCC)

- Reinsurance Risk Capital Charge (RICC)

- Market Risk Capital Charge (MRCC)

- Liability Risk Capital Charge (LRCC)

- Operational Risk Capital Charge (OPCC)

- Surrender Value Capital Charge (SVCC)

The formula is as follows:

$$
\begin{aligned}
& \mathrm{RCR}=\text { Maximum of SVCC } \\
& \text { or }\left((\mathrm{CRCC}+\mathrm{COCC}+\mathrm{RICC}+\mathrm{MRCC})^{2}+\mathrm{LRCC}^{2}+\mathrm{OPCC}^{2}\right)^{0.5}
\end{aligned}
$$


CRCC is calculated as the multiple of the admissible value of each asset category into the risk charge factor applicable to its asset quality.

COCC is calculated as a $100 \%$ risk charge on Inadmissible Assets which are not a TAC Deduction.

MRCC the aggregate of the following:

- Interest Risk Capital Charge (irCC)

- Credit Spread Risk Capital Charge (cpCC)

- Equity Risk Capital Charge (eqCC)

- Property Risk Capital Charge (prCC)

- Gold Risk Capital Charge (grCC)

- Unit Trust/Mutual Fund Risk Capital Charge (utCC)

irCC is the minimum of the up-shock and down-shock scenarios of mismatch between asset and liabilities valued at present. Here, the asset and liability cash-flows are discounted factoring fixed shock scenarios and Risk Free Rates (RFR). RFR is an indicative forward rate of return which is the excess of current Treasury bond yield over current inflation rate [25]. cpCC is calculated in a similar manner by discounting cash flows of assets bearing credit risk by factoring RFR and shock scenarios.

eqCC imposes risk charge factors on Listed Equity of non-related parties, Listed Equity of related parties and Unlisted Equity of non-related parties in the amount of 35\%, 45\% and 45\% respectively. Equity is valued at current market price.

prCC and grCC bear risk charge factors of $25 \%$ and $15 \%$ respectively and is charged on its admissible exposure value.

utCC imposes risk charge factors based on the underlying instrument of the relevant Unit Trust Funds, as per Table 1.

Table 1. Underlying Asset Contribution to MRCC through utCC.

\begin{tabular}{cc}
\hline Underlying Asset & Risk Charge Factor $^{\mathrm{a}}$ \\
\hline $\begin{array}{c}\text { Government Securities and Debt Securities/Deposits } \\
\text { guaranteed by Government }\end{array}$ & $0.0 \%$ \\
Money market instruments, including cash & $1.6 \%$ \\
Ordinary shares & $35.0 \%$ \\
Debt securities and corporate debt & $4.0 \%$ \\
Property & $25.0 \%$ \\
Other & $15.0 \%$ \\
\hline
\end{tabular}

a. as a percentage of Market Value as of effective date.

Unit Trust Funds are valued on current unit price. Unit Prices are calculated based on the yield and security of underlying assets.

RICC imposes risk charge factors on the net amounts receivable by insurers for less than six months and ceded policy liabilities based on the Counterpart Risk of Reinsurers.

LRCC is the maximum of zero or the difference between base and stressed 
Market Value of Net Liabilities. Liability cash flows are valued at present, factoring in RFR. OPCC imposes a risk charge factor of $1 \%$ on total Risk-Weighted Assets.

SVCC is the positive difference between Aggregate Surrender Value of Liabilities at Fund Level and the net Market Value of Liabilities.

It can be deduced that CAR is heavily influenced by external forces. Valuation of assets and liabilities are based on economic indices such as interest rates, exchange rates, stock prices, current purchasing power and other financial instrument yields. It is also impacted by social demographics such as quality of life, current trends, risk sentiment and strong societal beliefs through sales volumes. Additionally, idiosyncratic factors such as the strategic competence are reflected through operational margins as the company's technical and technological competencies are indicated by efficiency levels.

\subsection{Relationship between Economic Output and Economic Indicators}

Data collected from public databases such as IRCSL, CBSL, CSE and Department of Census and Statistics from 2013 to 2019 were subjected to Regression, Pearson's Correlation Coefficient calculation, trend analysis, scenario analysis and stress testing in order to determine the impact of external forces on the performance of the Insurance Industry [26]-[32].

\section{1) Trend Analysis of Economic Output and Economic Performance}

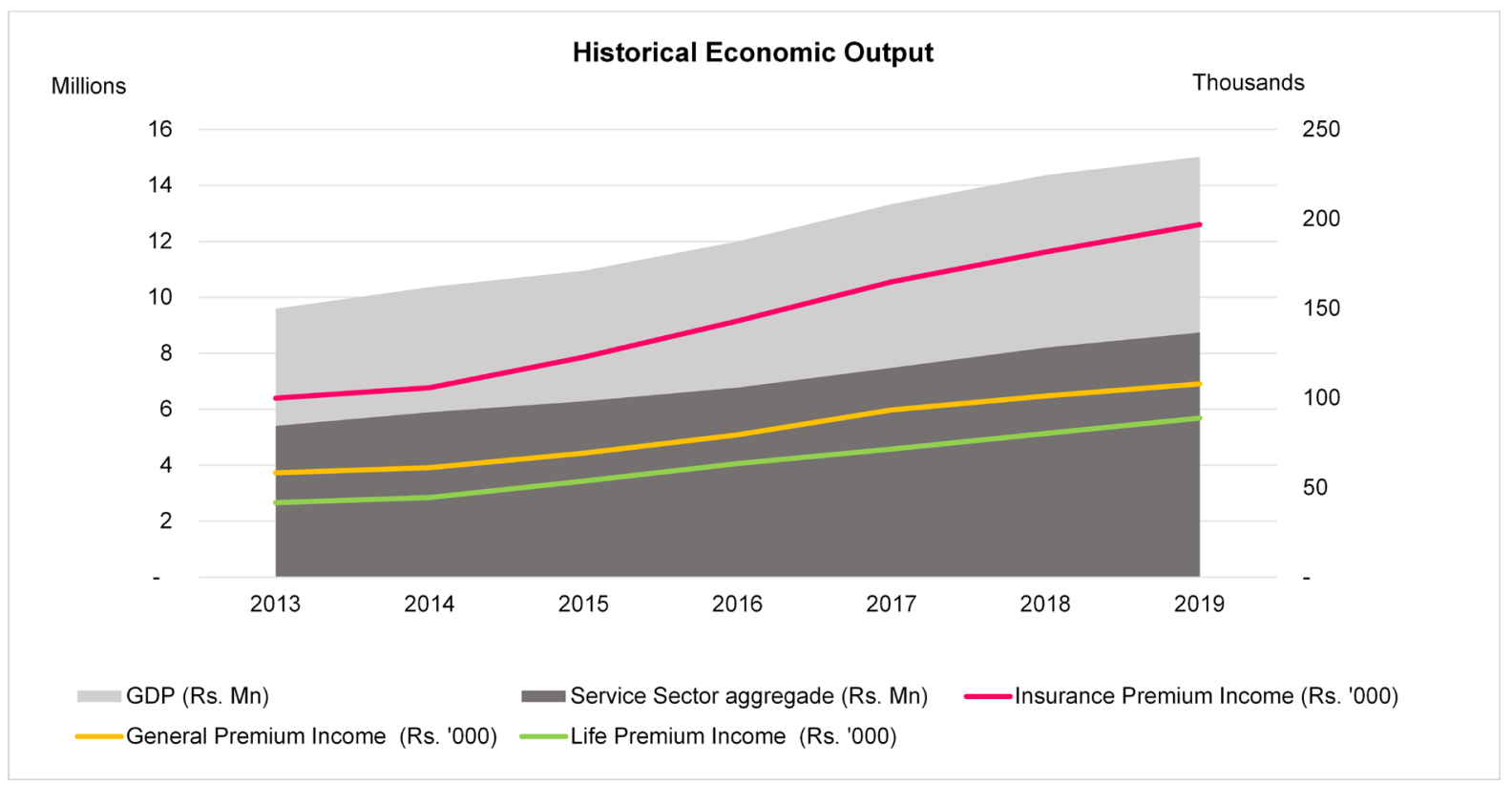

Figure 1. Historic economic output.

GDP, Service Sector and Insurance Premiums have a positive relationship as observed in Figure 1. However, the strength of the relationship seems to vary as observed from the curve slopes. This is due to increase of disposable income with the continuous growth of GDP. 


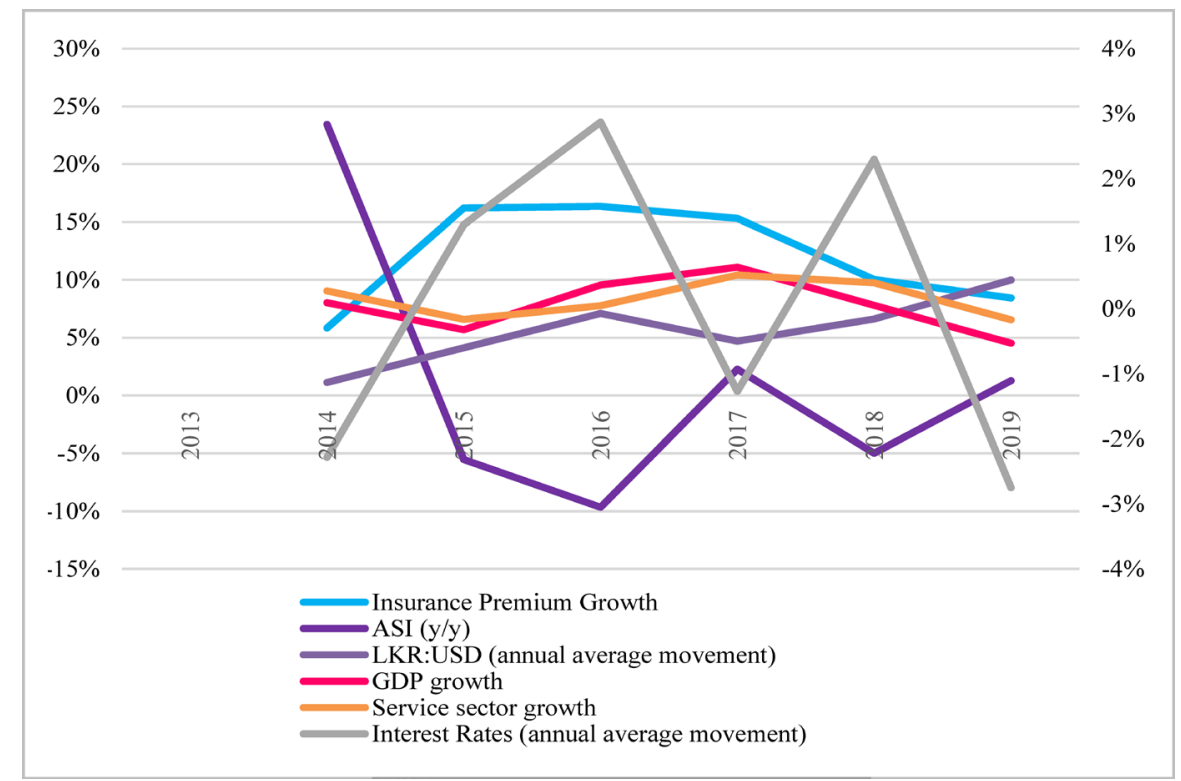

Figure 2. Historic economic performance vs. movement of indices.

Investors tend to make riskier investments in order to maximize returns during low risk periods. However, when the risk sentiment begins to worsen, the market produces a natural risk off phenomena where investors abandon low risk assets and flee to safe heavens as was prominent during the COVID-19 period [33]. This is evidenced by the inverse relationship between ASI and RFR as shown in Figure 2.

The relationship between the Exchange Rates and Insurance Premium Growth was positive up until 2019. Given the low economic stimulus prevalent in the country observed through low credit growth, CBSL eased monetary policy by way of continuously reducing policy rates, statutory reserves and bank rates while managing the liquidity reserves through issuance and repurchase of Government Securities [34].

Growth of Insurance Premiums and Service sector is observed to have a positive relationship.

2) Relationship between Economic Output and the movement of Economic Indices

Table 2. Pearson's Correlation Coefficient (against GDP).

\begin{tabular}{cc}
\hline Pearson's Correlation Coefficient between GDP and; & \\
\hline Insurance Premium Income & 0.9971 \\
General Premium Income & 0.9973 \\
Life Premium Income & 0.9947 \\
Service Sector aggregate & 0.9974 \\
\hline
\end{tabular}

The Insurance sector and its sub-sectors as well as the service sector have a strong positive correlation with GDP as observed in Table 2. Therefore, both positive 
and negative shocks on GDP will have a direct impact on the sectors proportionately.

Table 3. Pearson's correlation coefficient (against interest rates volatility).

\begin{tabular}{cc}
\hline Pearson's Correlation Coefficient between Interest Rate Movement and; & \\
\hline GDP growth & 0.224 \\
Service sector growth & 0.000 \\
Insurance Premium Growth & 0.602 \\
General Premium Growth & 0.424 \\
Life Premium Growth & 0.717 \\
ASI (y/y) & $(0.740)$ \\
LKR:USD (annual average movement) & 0.109 \\
\hline
\end{tabular}

Interest rates movement and Insurance Premium growth has a strong positive correlation while Interest rates movement and ASI growth has a strong negative correlation as observed in Table 3. This is evidenced by the boost in ASI witnessed during monetary policy easing and the dips seen during high inflationary environments [35] [36] [37].

However, Interest rates movement has a weak positive correlation with GDP which indicates that interest inelastic sectors contribute massively to GDP.

Table 4. Pearson's correlation coefficient (against exchange rate movement).

\begin{tabular}{cc}
\hline Pearson's Correlation Coefficient between LKR:USD Movement and; & \\
\hline GDP growth & $(0.344)$ \\
Service sector growth & $(0.391)$ \\
Insurance Premium Growth & 0.106 \\
ASI $(\mathrm{y} / \mathrm{y})$ & $(0.633)$ \\
\hline
\end{tabular}

The exchange rate movement has low negative correlations with GDP growth and service sector growth as observed in Table 4. However, insurance premium growth has a low positive correlation indicating a low level of influence. ASI has a strong negative correlation with exchange rate movement.

The GDP growth rate directly impacts the disposable income and thereby the purchasing power which heavily influences the service sector and insurance industry. Therefore shocks on GDP through components such as Trade, Credit Growth, Remittances, Tourism, FDI's must be factored in when assessing risks to the Insurance Industry.

The positive and negative relationships interest rate growth has with insurance premium growth and ASI respectively can be used to hedge against each other. If the risk management system can predict a shortfall on the industry, resources can be deviated from business acquisition to investments thereby negating the overall impact on capital. 
Despite the positive and negative relationship between LKR: USD movement and Interest rates and ASI respectively, given its opposing proportions interest rates and ASI cannot be hedged against each other efficiently.

Table 5. Pearson's correlation coefficient (against ASI movement).

\begin{tabular}{cc}
\hline Pearson's Correlation Coefficient between YoY ASI and; & \\
\hline Insurance Premium Growth & $(0.739)$ \\
General Premium Growth & $(0.576)$ \\
Life Premium Growth & $(0.804)$ \\
\hline
\end{tabular}

The strong negative correlation as observed in Table 5 indicates that ASI and Insurance act as substitute products. The strong negative correlation with Life premium growth is prudent as Life insurance products are long term investments while the equities are mostly short term investments. Hence, the direction of both depends on the country's GDP growth as well as the risk sentiment.

It can be deduced that GDP growth and interest rates directly influence the performance of the Insurance Sector while ASI inversely influences the performance of the Insurance Industry, specifically Life Insurance. Therefore, the impact on Life Insurance Premium growth can be forecasted by multiplying the Coefficient with forecasted movement of GDP and Interest rates.

\subsection{Impact of Interest Rates and Premium on Firm Assets}

Table 6. Pearson's correlation coefficient (against ASI movement).

\begin{tabular}{cc}
\hline Pearson's Correlation Coefficient between YoY ASI and; & \\
\hline Interest Rates and Long Term Insurance Assets & 0.053 \\
Long Term Insurance Assets and Premium & 0.725 \\
\hline
\end{tabular}

Assets have higher positive correlation with Premium than Interest as observed in Table 6. This is because the Asset Base largely funded by premium cash flows in the Life Insurance Sector and is therefore funded mainly through Liabilities.

Available information was insufficient to assess the same for liabilities.

\subsection{Main Driver of Liabilities}

The largest portion of Liability in an Insurance Firm is the Life Fund. As the Life Fund is the aggregate of all policies, it is entirely sales driven. Life Insurance Agents generated 86.93\% Gross Written Premium in 2018. The distribution channels for Life Insurance has expanded to include Agents, Brokers, Other sales force, Direct and Bancassurance. The newest channel in the pipeline is Micro Insurance but only a handful of players have penetrated the market.

Sales performance depends on idiosyncratic factors such as marketing strategy, competence of the sales force, corporate management and financial management as well as external factors such as economic growth and purchasing power. 


\subsection{Influencers of CAR}

Given the above analysis, it can be deduced that the main influencers of CAR are domestic economic growth, interest rates, sales and capital management. The core function of Capital Management is to realise Corporate Objectives while steering the company through risks.

For efficient strategy formulation and capital allocation, the company must quantify risks. This can be done using the RBC Rules (Section A) by cascading risks down to sub components, Credit Risk, Concentration Risk, Market Risk, Liability Risk, Reinsurance Risk, and Operational Risk.

\section{Derivation of Quadratic Equations for Risk Charges}

It has been deduced that the main influencers of CAR are domestic economic growth, interest rates, sales and capital management, out of which economic growth and interest rates are external volatility variables. Therefore, majority of Risk Charges can be derived as an expression of these volatility elements.

If we take the customize the Brownian motion formula derived in the Literature review section;

$$
y^{*}(t)=\mu t+\beta \tau^{*}(t)+\int \sqrt{\tau(s) \mathrm{d} w(s)^{1}}
$$

However, with the attempt to understand the basics of the model, it is prudent to build up from the most simplistic random walk formula;

$$
P_{t}=P_{(t-1)}+\mu_{t}+\propto
$$

Taking Interest Risk Capital Charge (irCC) as the example, the following formula can be derived.

Segregate interest sensitive assets and apply the formulae separately

$$
\text { Forward Bond Value }=P_{(t-1)}+\mu_{t}+\propto
$$

where;

$P_{(t-1)}=$ Previous real time valuation of Bonds.

$\mu_{t}=$ Random Shock (Independent movement).

$\propto=$ Constant (Dependent movement).

If the influence of interest rates on bonds is relatively direct, then the constant can be derived through the regression coefficient. On the other hand, given that changes announced at the bi-monthly monetary policy review by the CBSL contributes largely to the independent movement, a qualitative metric can be used here to predict the direction of the decision taken at the upcoming monetary policy review meeting and to thereby adjust the constant. Therefore, irCC will be the summation of all interest sensitive asset categories subjected to the aforementioned methodology.

eqCC can be derived in a similar yet indirect manner. Given that the Equity market responds indirectly to the changes in the interest rates, the change in ASI can be derived as an expression of the change in short term interest rates.

The formulae derived for the different interest sensitive assets can be indirect- 
ly linked to the Liability Risk Capital Charge (LRCC) computation. Given that the same interest rate forecast applies to Liabilities as well, the same independent movement can be taken while the constant has to be derived separately for each policy/rider as per the historic regression analysis.

Conversely, CRCC, COCC and RICC are dependent on the future counterpart rating. Therefore, an internal credit rating system must be developed to annually (for practical purposes) forecast any rating changes of counterparts. This must be dependent on the company's risk appetite statement as well.

OPCC depends mainly on the other risk charges and sales. Given that sales forecast is the cornerstone is financial planning, this paper assumed that there is a solid system in place for this purpose.

SVCC can hence be auto-calculated as liability metrics are being forecasted through LRCC.

\section{Conclusion}

\subsection{Influencers of CAR}

1) Forecasting each sub-risk category

RBC Rules under the Insurance Act of Sri Lanka provides a comprehensive model for calculating CAR. Here, TAC is divided by RCR and RCR is calculated as the aggregate of sub Risk Categories, namely Credit Risk, Concentration Risk, Liability Risk, Operational Risk, Reinsurance Risk and Market Risk. The base of Required Capital (RCR) is a series of risk charges for all identified risks clubbed within sub-categories.

Life Insurance is heavily influenced by GDP and Interest rates, which act as the base of volatility for independent variables such as Exchange Rates and ASI. Business and Investor confidence influences market rates. However, the overall market direction is regulated heavily through CBSL in order to stimulate economic growth through a private credit uptick.

CRCC and RICC can be forecasted by projecting the credit rating of counterparts through internal rating exercises. COCC, eqCC, grCC, prCC and utCC can be regulated through predetermined investment limits enforced through the Treasury Middle Office. Here, the asset portfolios can be stressed using various assumption based scenarios to derive the optimum mix that results in the desired level of Risk Charges.

irCC can be calculated by stressing asset cash flows as per assumption based scenarios.

In order to forecast LRCC, sales, pricing strategy and market rates must all be forecasted to ascertain the liability movement. Efficiency standards and management styles must be predetermined in order to incorporate projected profits into the OPCC calculation.

\section{2) Derivation of a Quadratic Equation for Capital}

The underlying Independent variable which impacts the entirely of the Industry is Policy Decisions. Shortcomings in GDP expectations due to the decline in 
trade, remittances, FDI, private credit and reserves are compensated through periodic Monetary and Fiscal policy reviews. These in turn result in volatility in terms of interest rates, GDP, exchange rates and demand. Therefore, the first instance of Brownian motion application must be between Policy review expectations and the resultant change in economic metrics. These relationships much then be re-expressed as a multiple of one or two independent variables. This enables the model to express the RBC formulae through the selected independent variables thereby giving a near-accurate quadratic equation for capital projection.

\subsection{Literature and Observation}

The RBC Rules calculate CAR in a similar manner to that of Boonen's SCR model with slight differences. The SCR only takes into account Interest, Equity and Longevity Risk while RBC includes a wider spectrum. However, this makes forecasting more difficult under the RBC model than the SCR model. The principle behind $\mathrm{RBC}$ is similar to the base of VaR, the only difference is VaR being undefined while $\mathrm{RBC}$ provides a risk model.

The EWMA method is not practical as it assumes that the market follows a normal distribution. The ARCH and GARCH models were superseded by the Stochastic Volatility Model.

\subsection{Limitations of the Observed Solution}

While the mathematics provide a sound basis of forecasting, it is entirely based on the relationship between policy decisions and resultant variable volatility. Therefore, the most prudent methodology is to predict the first instance of policy review by way of assessing the necessity of such a measure. This gives an indication as to the magnitude of the necessity of change and the magnitude of required change. If the volatility of each variable can then be integrated into a mass economic volatility formulae, much of the resultant impacts on many industries can then be quantified using the model proposed in this paper.

However, such mass integration is yet to be initiated on an academic level in Sri Lanka. Standalone initiation itself is insufficient and impractical due to the volatile nature of the economy. Therefore, quantification of the relationship between policy decisions and macroeconomic variables must be an ongoing research project with committed veterans of the industry as well as skilled statisticians and developers.

The same is true in terms of application of the model proposed within this paper on any one Insurer. The relationships must be re-evaluated and updated constantly as per the changing trends. The country currently does not have a committed line of research in this regard.

\subsection{Opportunities Arising from This Paper}

The recommendations stipulated in section 6.3 can be applied for any country or 
region. Such a mass-scale forecasting of macroeconomic variables provides an economic forecasting base for all industries within the selected region. The proposed capital projection model can then be customized and easily implemented within any industry. This provides regulators with a risk-weighted view of individual companies as well as industries as a whole which in turn improves the accuracy and quality of policy decision making within a certain region.

\section{Conflicts of Interest}

The author declares no conflicts of interest regarding the publication of this paper.

\section{References}

[1] Randiwela, P., Wijerathne, J. and Hettiarachchi, T. (2014) Determinants of Growth in Life Insurance Policies in Sri Lanka. Cambridge Conference Business \& Economics, Cambridge, 1-2 July 2014, 1-25.

[2] Gunawardane, N., Munasinghe, A. and Dissanayake, D. (2016) Relationship between Perceived Brand Equity and Purchase Intention of Life Insurance Brands in Sri Lanka: A Concept. International Journal of Business and Management Invention, 5, 106-111.

[3] Kozmenko, O. and Oliynyk, V. (2015) Statistical Model of Risk Assessment of Insurance Company's Functioning. Investment Management and Financial Innovations, 12, 189-194. https://doi.org/10.21511/imfi.12(2-1).2015.01

[4] Dowd, K., Bartlett, D., Chaplin, M., Kelliher, P. and O’Brien, C. (2008) Risk Management in the UK Insurance Industry: The Changing State of Practice. International Journal of Financial Services Management, 3, 5. https://doi.org/10.1504/IJFSM.2008.016696

[5] Ivanovna, K., Vladimirovna, M. and Turgaeva, A. (2018) Insurance Risks Management Methodology. Journal of Risk and Financial Management, 11, 75.

https://www.researchgate.net/publication/328637145_Insurance_Risks_Managemen t_Methodology https://doi.org/10.3390/jrfm11040075

[6] Angima, C., Mwangi, M., Kaijage, E. and Ogutu, M. (2017) Actuarial Risk Management Practices, Underwriting Risk and Performance of P \& C Insurance Firms in East Africa. European Scientific Journal, 13, 207. https://doi.org/10.19044/esj.2017.v13n22p207

[7] Albrecher, H., Bommier, A., Filipovic, D., Koch-Medina, P., Loisel, S. and Schmeiser, H. (2019) Insurance: Models, Digitalization, and Data Science. SSRN Electronic Journal. https://doi.org/10.2139/ssrn.3382125

[8] Hillston, J., Tribastone, M. and Gilmore, S. (2011) Stochastic Process Alge-Bras: From Individuals to Populations. The Computer Journal, 55, 866-881. https://doi.org/10.1093/comjnl/bxr094

[9] Saunders, M.N.K., Lewis, P. and Thornhill, A. (2019) Research Methods for Business Students. 8th Edition, Pearson, New York.

[10] Liberati, A., Altman, D.G., Tetzlaff, J., Mulrow, C., Gøtzsche, P.C., Ioannidis, J.P.A., Clarke, M., Devereaux, P.J., Kleijnen, J. and Moher, D. (2009) The PRISMA Statement for Reporting Systematic Reviews and Meta-Analyses of Studies That Evaluate Health Care Interventions: Explanation and Elaboration. Journal of Clinical Epide- 
miology, 62, e1-e34. https://doi.org/10.1016/j.jclinepi.2009.06.006

[11] Denscombe, M. (2017) The Good Research Guide: For Small-Scale Social Research Projects. 6th Edition, Open University Press, London.

[12] Sherris, M. (2014) Risk Based Capital and Capital Allocation in Insurance. The Journal of Risk Management, 25, 157-190. https://doi.org/10.21480/tjrm.25.2.201409.006

[13] Kengatharan, L. (2016) Capital Budgeting Theory and Practice: A Review and Agenda for Future Research. Applied Economics and Finance, 3, 15-38. https://doi.org/10.11114/aef.v3i2.1261

[14] Dacorogna, M. (2018) A Change of Paradigm for the Insurance Industry. Annals of Actuarial Science, 12, 211-232. https://doi.org/10.1017/S1748499518000040 https://www.researchgate.net/publication/323396383_A_change_of_paradigm_for_ the_insurance_industry/link/5b8eae9045851540d1c878ff/download

[15] Crouhy, M., Turnbull, S. and Wakeman, L. (1999) Measuring Risk-Adjusted Performance. Journal of Risk, 2, 5-35.

[16] Abad, P., Benito, S. and López, C. (2014) A Comprehensive Review of Value at Risk Methodologies. The Spanish Review of Financial Economics, 12, 15-32. https://www.sciencedirect.com/science/article/pii/S217312681300017X https://doi.org/10.1016/j.srfe.2013.06.001

[17] Perry, M.B. (2011) The Exponentially Weighted Moving Average. Wiley Encyclopedia of Operations Research and Management Science.

[18] Engle, R. (1982) Autoregressive Conditional Heteroscedasticity with Estimates of the Variance of United Kingdom Inflation. Econometrica, 50, 987-1007. https://doi.org/10.2307/1912773

[19] Hassan, D. and Hady, A. (2014) Modeling Volatility with GARCH Family Models: An Application to Daily Stock Log-Returns in Pharmaceutical Companies. Pensee Journal, 76, 52-69.

https://www.academia.edu/10167218/Modeling_Volatility_with_GARCH_Fami-ly_ Mod-

els_An_Application_to_Daily_Stock_Log_returns_in_Pharmaceutical_Companies

[20] Lavenda, B. (2019) Nonequilibrium Statistical Thermodynamics.

[21] Barndorff-Nielsen, O.E., Nicolato, E. and Shephard, N. (2002) Some Recent Developments in Stochastic Volatility Modelling. Quantitative Finance, 2, 11-23. https://doi.org/10.1088/1469-7688/2/1/301

[22] Boonen, T.J. (2017) Solvency II Solvency Capital Requirement for Life Insurance Companies Based on Expected Shortfall. European Actuarial Journal, 7, 405-434.

https://www.ncbi.nlm.nih.gov/pmc/articles/PMC5744639 https://doi.org/10.1007/s13385-017-0160-4

[23] Sedgwick, P. (2012) Pearson's Correlation Coefficient. BMJ, 345, e4483-e4483. https://doi.org/10.1136/bmj.e4483

[24] Mondal, H. and Mondal, S. (2016) Sample Size Calculation to Data Analysis of a Correlation Study in Microsoft Excel ${ }^{\circledR}$ : A Hands-On Guide with Example. International Journal of Clinical and Experimental Physiology, 3, 180. https://doi.org/10.4103/2348-8832.196896

[25] Ilomäki, J. and Laurila, H. (2017) Real Risk-Free Rate, the Central Bank, and Stock Market Bubbles. Journal of Reviews on Global Economics, 6, 420-425. https://doi.org/10.6000/1929-7092.2017.06.43

[26] Department of Census and Statistics (2020) Gross Domestic Product (GDP) and 
Other Macroeconomic Indicators. Department of Census and Statistics, Colombo. http://www.statistics.gov.lk/NationalAccounts/dcsna_r2/reports/2020.03.31/2019_A nnual_(2020_03_31)pdf

[27] CBSL (2020) Industry Highlights-Q4 of 2019 vs Q4 of 2018.

[28] CBSL (2019) Industry Highlights-Q2 of 2019 vs Q2 of 2018.

[29] IRCSL (2019) Statistical Review. IRCSL, Colombo. https://ircsl.gov.lk/insurance-sector/industry-performance/previous-year.html

[30] IRCSL (2016) Statistical Review. IRCSL, Colombo. https://ircsl.gov.lk/insurance-sector/industry-performance/previous-year.html

[31] CBSL (2019) Industry Highlights-Q1 of 2019 vs Q1 of 2018.

[32] CBSL (2019) Industry Highlights-Q3 of 2019 vs Q3 of 2018.

[33] Quindo, K. (2020) Risk Off as Markets Plunge. Fx Street. https://www.fxstreet.com/analysis/risk-off-as-markets-plunge-202009090056

[34] CBSL (2020) The Central Bank of Sri Lanka Further Reduces the Statutory Reserve Ratio. CBSL, 16 June 2020.

[35] EconomyNext (2018) Sri Lankan Stocks Weakened by Rising Interest Rates, Political Uncertainty.

https://economynext.com/sri-lankan-stocks-weakened-by-rising-interest-rates-polit ical-uncertainty-10734

[36] Thishanthi, G.T. and Silva, N.K.L. (2015) The Effect of Monetary Policy on Stock Market in Sri Lanka. Department of Accountancy, University of Kelaniya, Kelaniya. https://www.researchgate.net/publication/286383817_The_Effect_of_Monetary_Pol icy_on_Stock_Market_in_Sri_Lanka/link/5668553d08ae7dc22ad255b1/download

[37] LBO (2019) Strong Possibility of a Rate Cut; Interest Rate Decline to Boost Stock Market: Capital Trust. Lanka Business Online.

https://www.lankabusinessonline.com/strong-possibility-of-a-rate-cut-interest-ratedecline-to-boost-stock-market-capital-trust 